d'Entremont, M. V., M. I. Hartley, and K. A. Otter. 2017. Comparing pre- versus postoperational movement of nocturnal migrants around a wind energy facility in northeast British Columbia, Canada. Avian Conservation and Ecology 12(2):3. https://doi.org/10.5751/ACE-01046-120203

Copyright (C) 2017 by the author(s). Published here under license by the Resilience Alliance.

Research Paper

\title{
Comparing pre- versus postoperational movement of nocturnal migrants around a wind energy facility in northeast British Columbia, Canada
}

Marc V. d'Entremont ${ }^{1}$, Isobel Hartley ${ }^{2}$ and Ken A. Otter ${ }^{2}$

${ }^{1}$ LGL Limited, ${ }^{2}$ Natural Resources and Environmental Studies, University of Northern British Columbia

\begin{abstract}
We used two data-recording, open-array marine surveillance radars to track microscale movements of nocturnal migrants at a wind energy project in northeast British Columbia during the preoperational (2008-2010) and operational periods (2011-2012). Data was collected during the peak periods of spring and fall passerine migration in each year. We measured bearing and altitude of nocturnal migrants, as well as the average number of migrants flying in the airspace closest to the wind turbines. Using weather data on wind direction and strength during the periods of monitored migration, we calculated flow-assistance of wind in aiding migration. Although there was greater flow-assistance to movement in spring over fall migration, we did not find a significant difference between the preoperational and operational periods in flow-assisted flight. The altitude at which migrants flew did differ with development phase of the wind facility; migrants flew at higher altitudes during years when the turbines were operational compared to preoperational years. Although the proportion of migrants detected in the airspace $0-150 \mathrm{~m}$ above ground level (agl), coinciding with turbine height, did not differ with season or operational phase of the installation, there was a reduction in the proportion of migrants in the airspace just above turbines (151-300 m agl) when turbines were operational. In general, though, the overall altitudes used by migrants were typically higher than turbine height, so the adjustments we documented would only further reduce what appear to be already low levels of collision risk at this particular facility. We discuss possible reasons why this facility appeared to induce low collision risk to migrants, and how this might inform siting decisions of other wind facilities.
\end{abstract}

\section{Comparaison des déplacements d'oiseaux migrateurs nocturnes avant et après la construction d'un parc d'éoliennes dans le nord-est de la Colombie-Britannique, Canada}

RÉSUMÉ. Nous avons utilisé deux radars de navigation maritime, à tableau ouvert et pouvant enregistrer des données, afin de suivre les microdéplacements d'oiseaux migrateurs nocturnes sur le site d'un projet de parc d'éoliennes dans le nord-est de la ColombieBritannique en périodes préopérationnelle (2008-2010) et opérationnelle (2011-2012). Les données ont été récoltées durant les périodes de pointe de la migration des passereaux au printemps et à l'automne chaque année. Nous avons mesuré la position et l'altitude des migrateurs nocturnes, et le nombre moyen de migrateurs volant dans l'espace aérien le plus près des éoliennes. Au moyen de données météorologiques sur la direction et la force du vent durant les périodes de migration suivies, nous avons calculé l'apport du vent pour faciliter la migration. Même si l'apport du vent était plus élevé pour les déplacements au printemps qu'à l'automne, nous n'avons pas trouvé de différence significative pour les déplacements facilités par le vent entre les périodes préopérationnelle et opérationnelle. L'altitude à laquelle les migrateurs ont volé a varié pendant la construction du parc d'éoliennes; les migrateurs ont volé à des altitudes plus élevées durant les années où les éoliennes étaient en opération comparativement aux années preopérationnelles. Même si la proportion de migrateurs détectés dans l'espace aérien compris entre 0 et $150 \mathrm{~m}$ au-dessus du sol (AGL) - ce qui correspond à la hauteur des éoliennes - n'a pas varié selon les saisons ou lors de la mise en opération du parc, il y a eu une diminution de la proportion de migrateurs dans l'espace aérien juste au-dessus des éoliennes (151-300 m AGL) une fois que les éoliennes ont été opérationnelles. Toutefois, en général, les altitudes utilisées par les migrateurs étaient typiquement plus hautes que les éoliennes, de sorte que les ajustements d'altitude que nous avons documentés contribueraient à réduire encore plus ce qui semble déjà être de faibles risques de collision à ce parc en particulier. Nous traitons des raisons possibles pouvant expliquer que ce parc semble présenter peu de risques de collision pour les migrateurs et comment ceci peut contribuer à orienter les décisions touchant la localisation d'autres parcs d'éoliennes.

Key Words: collision risk; conservation; movement; nocturnal migrants; radar; wind energy

\section{INTRODUCTION}

In North America, passerine birds migrate in a broad-front fashion between breeding and nonbreeding grounds along relatively well-documented corridors, stopping for periods during these migrations to rest and replenish fuel stores (Gauthreaux
1991, Able 2004, Liechti et al. 2013). At this broad spatial scale (macroscale of $100 \mathrm{~s}$ of $\mathrm{km}$ ), directionality of migration movements are predictable (Mabey 2004). The site-specific timing and spatial patterns of movements of migratory birds at individual locations (microscale of $1-10 \mathrm{~km}$ ) along these 
corridors are less understood, particularly because variation in weather and topography can influence these patterns (Mabey 2004, Liechti et al. 2013, Pocewicz et al. 2013). Understanding movement patterns on these smaller microscales, though, is required to identify whether anthropogenic developments, such as wind installations or other tall structures built along migration corridors, can lead to migratory disruption or collision risk.

Nocturnally migrating passerines have been recorded at a range of altitudes up to and over $5000 \mathrm{~m}$ (Liechti and Schaller 1999, Liechti and Schmaljohann 2007, Schmaljohann et al. 2009), but in some instances a significant number of birds have been found to migrate in the lower altitudes, below $1500 \mathrm{~m}$ above ground level (agl; Able 2004, Mabee et al. 2006, Longcore et al. 2008, Schmaljohann et al. 2008, Dokter et al. 2011, Kemp et al. 2013). Depending on site, this range of lower flight altitudes may occur in one season only (Schmaljohann et al. 2009) or during both spring and fall movements (Bruderer 1997). Migrants will typically climb to altitudes where they encounter favorable winds, which are used to maximize flight ranges on a given amount of fuel stores (Klaassen et al. 2012, Marques et al. 2014). Wind layers at greater heights above ground often are less subject to surface friction, and thus create more stable and predictable winds to facilitate migration (Klaassen et al. 2012, Dokter et al. 2013), however, choice of altitudes for migratory movement must also be balanced against constraints imposed by extreme temperatures and lower oxygen for respiration with increasing altitude (Able 2004, Schmaljohann et al. 2008). This results in nocturnal migrants settling their movement each night within the most profitable wind layer available that balances these factors (Kemp et al. 2013). Flight altitudes generally peak early in the evening and are typically higher than those observed later in the evening/ early morning (Mabee et al. 2006); this altitudinal profile of nocturnal migrants during a night, though, is influenced by topography and wind (Bruderer 1997). Because of the lower flight altitudes relative to ground level imposed on birds when moving over mountain ranges, migrants can be exposed to terrain forced winds that may oppose the principal direction of migration (Bruderer 1997, Liechti et al. 2013). Under such conditions, the flight paths of migrants may be scattered and subject to topographic features and structures on the landscape (Mabey 2004), further adding to the unpredictable patterns of microscale movement.

Understanding microscale movement patterns, and the factors that govern them, may prove a useful tool in determining the potential impact of wind power development on passerine migration. During the spring and fall periods, nocturnally migrating passerines are the most abundant avian group encountering wind energy facilities (Marques et al. 2014), which is reflected in the high proportion of passerine carcasses that are typically found at wind projects (Johnson et al. 2002, Zimmerling et al. 2013, Erickson et al. 2014). Passerines typically compose $80 \%$ of all fatalities at such installations, most of which involve nocturnal migrants (Mabee et al. 2006, Kuvlesky et al. 2007). Although this likely constitutes a small fraction of overall population sizes (Loss et al. 2013, Zimmerling et al. 2013), effects on birds remains an integral component of environmental assessments for wind energy developments (Zimmerling et al. 2013) because of their potential to add to cumulative impacts on avian populations. The general knowledge of the interactions between birds and wind turbines has substantially increased since the infancy of the wind energy industry (Marques et al. 2014), but before-and-after development studies on how wind facilities affect the migratory behavior of passerines are still sparse (Kuvlesky et al. 2007).

Avoidance behavior by nocturnal migrants will strongly influence the mortality rates observed at wind energy projects (Chamberlain et al. 2006), but the scale of avoidance to wind turbines for nocturnally migrating birds is almost unknown (Liechti et al. 2013). Two levels of magnitude are expected for the avoidance of wind turbines: (1) macroscale avoidance where birds alter their flight path to circumnavigate an entire wind energy installation; and (2) microscale avoidance where birds alter their flight movements while they are passing within the boundaries of a wind energy installation (Marques et al. 2014). In this study, we documented the microscale patterns of nocturnal migrant movements through a $144 \mathrm{MW}$ wind energy project in northeast British Columbia, Canada. Using X-band marine radar units, equipped with an electronic interface system, we recorded the movement patterns and altitudes of migrants to determine if spatial patterns of flight differ between preoperational and operational periods of the wind energy facility.

\section{METHODS}

\section{Study area}

We collected radar data on nocturnal migrants at the Dokie I Wind Energy Project located in northeast British Columbia, Canada $\left(55^{\circ} 41^{\prime} 28^{\prime \prime} \mathrm{N} 12218^{\prime} 06^{\prime \prime} \mathrm{W}\right)$ during the spring and fall migration periods from 2008 to 2012 (Fig. 1). The site is located in the eastern foothills of what is considered the Northern Rockies, which lie in a north-northwest to south-southeast orientation. The project is situated on two ridges ranging in elevation from $1200 \mathrm{~m}$ to $1400 \mathrm{~m}$ above sea level. The project underwent site construction (roads, turbine pads, etc.) from 2008 2009. At this time five widely-spaced ( $>1 \mathrm{~km}$ apart) turbine towers were initially constructed, of which only two had blades attached and none contained any operational hydraulics, and so were inactive. Construction then halted until the late summer of 2010. Turbine erection resumed following our spring surveys, and several additional turbines were erected but nonoperational during the fall survey, and the full construction completed in the fall following our survey period. Turbines become operational and commenced energy production in early 2011 prior to the spring migration period of that year. The Dokie I Wind Energy Project is a 144 megawatts (MW) installation comprising 48 Vestas V90 3MW wind turbines that have a tower height of $80 \mathrm{~m}$, a rotor diameter of $90 \mathrm{~m}$ and a rotor swept area of $6362 \mathrm{~m}^{2}$. Fifteen turbines are placed on the smaller, southern ridge and 33 turbines on the larger, northern ridge. For analytical purposes, we considered the first three years of the study (2008-2010) the preoperational period for the wind energy facility and the final two years (2011-2012) to represent the operational period, based upon whether turbines were actively rotating during these periods.

\section{Data collection}

We recorded movement patterns of nocturnal migrants around the wind project using two Furuno X-band marine radar units (model 1954C, 12kW, 9,000 MHz, $1.83 \mathrm{~m}$ open array antennas 
with beam width of $1.9^{\circ}$ horizontal and $22^{\circ}$ vertical - Furuno Electric Company Ltd. Miki Japan) equipped with an electronic interface system (signal digitizer [XIR3000B] and WinHorizon software [Version 1.5.0.13 - Russell Technologies Inc., North Vancouver, BC; http://www.russelltechnologies.ca/). Details on radar set up and calibration of the avian detection system used are provided as supplementary material. One of the radar units was set in the surveillance position (antenna rotating on the typical horizontal axis) to record passage rates and determine bearing of migrants. This radar's antenna was custom angled upwards to $15^{\circ}$ such that the main lobes of the beam span from $\sim+4^{\circ}$ to $+26^{\circ}$ above the horizon. The second unit was set in the vertical position (radar mounted at $90^{\circ}$, so that the antenna rotated through the vertical axis) to record heights of targets. Both radars were set to $1.5 \mathrm{~km}$ detection range on short-pulse length $(80 \mathrm{~ns}$ at pulse repetition frequency $[\mathrm{PRF}]=2100 \mathrm{~Hz})$. Sea clutter and rain removal settings were turned off, and gain set at maximum level (76 on scale of $0-100$ ) that balanced maximum resolution without introducing clutter (see supplemental material for additional information on radar set up). These settings were standardized among years and the radars were set in the same locations each season. The radar units were set in locations where minimal interference from ground clutter was present. The horizontal radar was mounted approximately $2.0 \mathrm{~m}$ above ground and oriented to true north. The vertical radar was mounted approximately $1.5 \mathrm{~m}$ above the ground and the antenna was aligned with the proposed/constructed turbine arrays allowing us to determine heights of targets as they passed above the turbine strings (Fig. 1). Radars were generally operational from 21:00 to 05:00 each night in the spring and 20:00 to 06:00 in the fall, which reflected sunset to sunrise in each season. Recording dates varied slightly among years, but surveys were timed to coincide with the previously documented peak periods of spring passerine migration (mid- to late-May) and fall migration (late-August to early September) each year (Jacques Whitford-AXYS Ltd. 2006, Pomeroy et al. 2007).

Radar imagery was analyzed using radR (Taylor et al. 2010), an open-source, R-based platform (https://radr-project.org/). This platform uses algorithms to distinguish and track moving targets from stationary objects. radR uses the first five rotations of the radar to identify and ignore stationary returns. It then searches for detections moving in predictable paths, based on user inputs for specific variables, such as target size and the number of successive rotations on which targets are detected before initiating tracking. We tested a variety of settings for each of four userdefined settings that accounted for the greatest variability in detecting/tracking targets (see Table A1.1), utilizing the combination of settings that results in the highest congruence between known manually tracked targets and those autotracked by $\operatorname{radR}\left(\mathrm{R}^{2}=0.94\right.$; see Fig. A1.1). Output data on tracked targets from both radars were further processed in the statistical program R (R Development Core Team 2017) to compile specific data on track location, length, bearing, and speed (horizontal radar data). Height of targets as they passed over the vertical radars were determined at a detection range of $1.5 \mathrm{~km}$, but to further investigate the number of birds aloft in lower altitudes closer to the turbines, we also recorded the number of targets detected in six height categories $(0-150 \mathrm{~m}, 151-300 \mathrm{~m}, 301-450 \mathrm{~m}, 451-600$ $\mathrm{m}, 601-750 \mathrm{~m}$, and > $751 \mathrm{~m}$ agl; vertical radar data).
Fig. 1. Position and orientation of the radar sites surveyed from 2008 to 2012 in relation to the topography of the ridgelines at the Dokie I Wind Energy Project in northeast British Columbia $\left(55^{\circ} 41^{\prime} 28^{\prime \prime} \mathrm{N} / 122^{\circ} 18^{\prime} 06^{\prime \prime} \mathrm{W}\right)$. The $1.5 \mathrm{~km}$ radius circles represent the area of coverage for the surveillance (horizontal) radar. The dashed rectangular boxes represent the area of coverage for the vertical radars.

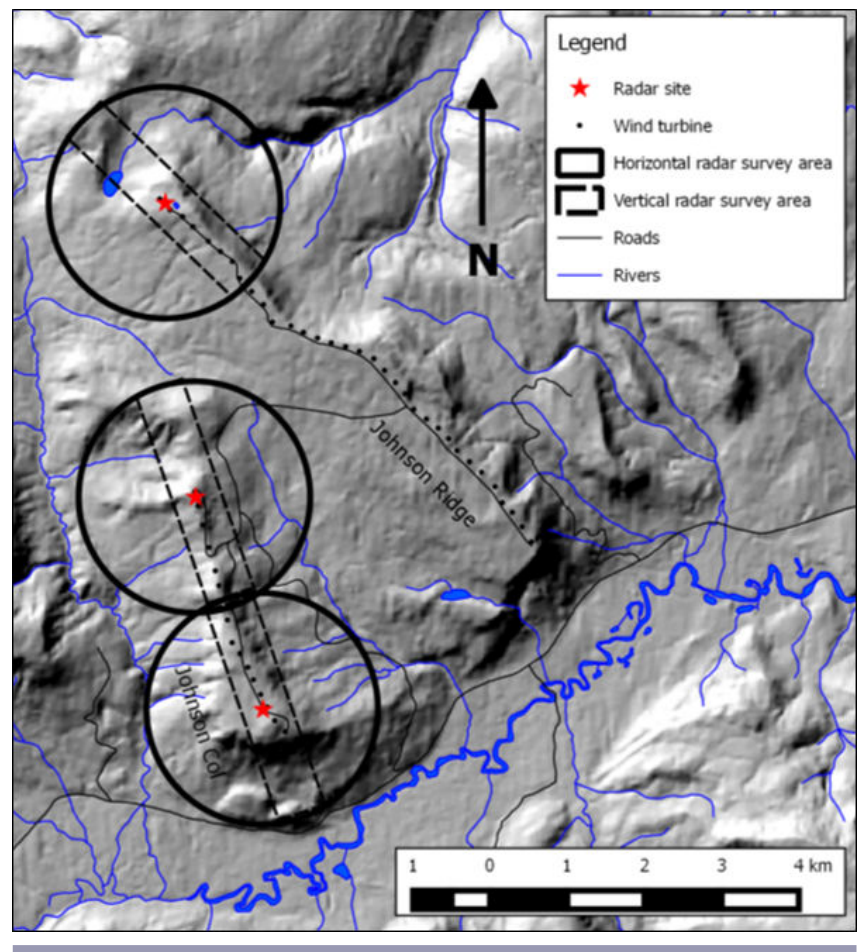

\section{Wind data}

We obtained wind vector data from the National Centers for Environmental Prediction (NCEP) North American Regional Reanalysis (NARR) dataset using the three hour composite data for the zonal wind ( $\mathrm{U}$ wind) and meridional wind ( $\mathrm{V}$ wind). The latitude and longitude of the study site was matched with the nearest NARR $32 \mathrm{~km}$ by $32 \mathrm{~km}$ grid cell center, which was approximately $10 \mathrm{~km}$ from the study site, and we obtained data from the $825 \mathrm{mb}$ pressure level, which corresponds to approximately $500 \mathrm{~m}$ agl at the study site. This altitude was chosen because it corresponded to average heights of migrants detected during preliminary analysis. We calculated the wind vector as the direction (degrees), with respect to true north, toward which the wind was blowing for each hour of surveying across both seasons and all years. For each period, we also recorded the wind speed in $\mathrm{m} / \mathrm{s}$.

\section{Quantifying flow-assisted movement}

Utilizing information on the average bearing and flight speed of migrants across years, coupled with the wind direction and speed for each hour of monitoring, we calculated a measure of flowassisted flight for migrants using the Wind Profit equation of Kemp et al. (2013). This equation utilizes the seasonal migratory "goal," the direction in which migrants are attempting to travel, 
Table 1. The total numbers of tracked avian targets detected by the horizontal radar, by season and year, across the survey period from 2008 to 2012 at the Dokie I Wind Energy Project in northeast British Columbia. Variation in the number of nights surveyed between season and years reflected both problems encountered with weather and equipment. Target numbers shown reflect exclusion of nonavian targets through application of filter expressions in radR.

\begin{tabular}{|c|c|c|c|c|c|c|c|c|c|c|}
\hline & \multicolumn{2}{|c|}{2008} & \multicolumn{2}{|c|}{2009} & \multicolumn{2}{|c|}{2010} & \multicolumn{2}{|c|}{2011} & \multicolumn{2}{|c|}{2012} \\
\hline & Spring & Fall $^{\dagger}$ & Spring & Fall & Spring & Fall & Spring & Fall & Spring & Fall \\
\hline Targets detected & 120,934 & - & 8506 & 655,103 & 28,199 & 158,750 & 150,334 & 379,968 & 164,665 & 617,355 \\
\hline $\begin{array}{l}\text { Number of nights } \\
\text { surveyed }\end{array}$ & 16 & - & 5 & 12 & 7 & 10 & 9 & 10 & 13 & 11 \\
\hline $\begin{array}{l}\text { Date range over } \\
\text { which sample } \\
\text { collected }\end{array}$ & $\begin{array}{l}11 \text { May- } \\
31 \text { May }\end{array}$ & - & $\begin{array}{l}12 \text { May- } \\
18 \text { May }\end{array}$ & $\begin{array}{l}26 \text { Aug- } \\
7 \text { Sep }\end{array}$ & $\begin{array}{l}19 \text { May- } \\
26 \text { May }\end{array}$ & $\begin{array}{l}25 \text { Aug- } \\
3 \text { Sep }\end{array}$ & $\begin{array}{l}19 \text { May- } \\
28 \text { May }\end{array}$ & $\begin{array}{l}24 \text { Aug- } \\
2 \text { Sep }\end{array}$ & $\begin{array}{l}18 \text { May- } \\
30 \text { May }\end{array}$ & $\begin{array}{l}19 \text { Aug- } \\
29 \text { Aug }\end{array}$ \\
\hline Hours surveyed & 99.9 & - & 34.3 & 112.5 & 23.0 & 83.6 & 57.6 & 70.7 & 91.6 & 94.0 \\
\hline Targets/hour & 1210.6 & - & 248.0 & 5823.1 & 1226.0 & 1898.9 & 2609.96 & 5374.4 & 1797.7 & 6567.6 \\
\hline
\end{tabular}

Fall 2008 - horizontal radar was nonoperational in the fall of this first year of data collection.

and the assumed average migratory flight speed that birds are attempting to maintain. We set the migratory goal as the average bearing of migrant targets detected on the horizontal radar for each season (all years combined), which we calculated across all individual tracks using CircStats (Agostinelli 2009) package in $\mathrm{R}$ (vs 3.4.0, R Development Core Team 2017). We also report the relative length vector of this average bearing (rho), which ranges from $0-1$ with higher values indicating a longer vector, e.g., more focused directionality to mean bearing. We assumed an average migratory flight speed of $12 \mathrm{~m} / \mathrm{s}$ (Bruderer and Boldt 2001, Kemp et al. 2013), which also closely matches the average flight speed of radar targets in our study under low-wind conditions (unpublished data). Kemp et al.'s (2012, 2013) flow-assisted flight (or Wind Profit) assumes that migrants attempt to maintain this migratory goal and average flight speed, and that the wind direction/wind speed can either assist this, e.g., a strong tailwind, or hinder this, e.g., strong headwind, objective. The flow-assisted value is a function of the angular difference between wind direction and the direction of the birds' migratory goal, taking into account the wind speed. Derived values are vector scores that range from $\sim+20$ (full tailwind at wind speed that provides full flight assistance to maintain migratory flight speed) to $\sim-20$ (a headwind that requires high energetic outlay from the migrant to maintain the target flight speed and bearing). All values between these indicate varying wind displacement for which the birds must partially compensate to maintain intended direction and speed.

We calculated the wind profit for each hour of monitoring for all nights across both seasons and all years for which radar data was gathered. We then used a General Linear Mixed Model (lme4 package for R; Bates et al. 2015) to compare the hourly flowassistance (dependent variable) offered to migrants by both season (spring vs fall) and operational phase of the project (preoperational vs operational; fixed effects) while controlling for variation from individual nights as a random effect.

\section{Migratory altitudes}

We determined flight altitudes (meters agl) of targets using the vertical radars as they passed above the installation. Radars have higher likelihood of detecting small targets closer to the radar, but simultaneously the spreading of the beam width means a larger volume of sky is sampled at greater distances. Although this provides a high likelihood, with the radar setting used, of detecting passerine-sized targets up to at least 1000-1200 m from the radar, and larger targets to the full $1500 \mathrm{~m}$ detection radius, the distribution of target heights was still slightly skewed. As a result, we used a General Additive Model (GAM) with a gamma function and log link using the mgcv package for R (Wood 2006) to compare the flight altitudes of migrants (dependent variable) in relation to the operational phase (preoperational vs operational) with hour of night after sunset as the smoothed function. Each season, spring and fall, was run as a separate model.

To further investigate the effect of turbine operation on migration, we determined the number of birds aloft in each $150 \mathrm{~m}$ height interval during the preoperational vs operational years. We compared the number of birds aloft in the $0-150 \mathrm{~m}$ height category - the heights overlapping the turbine area, and thus constituting the highest potential collision risk - with the total number of detected migrants in height bins $>150 \mathrm{~m}$, e.g., above turbines, using a generalized linear mixed model (glmer) in the package lme4 using a binomial model with a logit link. Operational phase (preoperation vs operational) was added as a fixed effect, and variation accounted for by individual nights added as a random effect. All graphics were created using either QGIS (vs 2.8), or the ggplot2 (Wickham 2009) package for R.

\section{RESULTS}

\section{Overall passage rates of migrants}

Over the five-year survey period we autotracked a total of $2,293,814$ aerial targets with the horizontal radar and a total of 598,834 aerial targets with the vertical radar (Tables 1 and 2) with the radR processing. Periods of poor weather were excluded from the survey effort, which partially explains the variation in annual and seasonal survey effort. Technical difficulties with the radar equipment also caused minor gaps in the collection of data and these periods were excluded from the survey effort. In general, more targets were detected by the horizontal radar because of the larger detection area being covered by the radars in their respective orientations. Finally, a higher number of targets were consistently detected in the fall migration (Tables 1 and 2). 
Table 2. The total numbers of tracked avian targets detected by the vertical radar, by season and year, across the survey period from 2008-2012 at the Dokie I Wind Energy Project in northeast British Columbia. Variation in the number of nights surveyed between season and years reflected both problems encountered with weather and equipment. Target numbers shown reflect exclusion of nonavian targets through application of filter expressions in $\operatorname{radR}$.

\begin{tabular}{|c|c|c|c|c|c|c|c|c|c|c|}
\hline & \multicolumn{2}{|c|}{2008} & \multicolumn{2}{|c|}{2009} & \multicolumn{2}{|c|}{2010} & \multicolumn{2}{|c|}{2011} & \multicolumn{2}{|c|}{2012} \\
\hline & Spring & Fall & Spring & Fall & Spring & Fall & Spring & Fall & Spring & Fall \\
\hline Targets detected & 23,875 & 45,125 & 3149 & 135,780 & 21,426 & 98,202 & 55,268 & 82,667 & 164,665 & 85,674 \\
\hline $\begin{array}{l}\text { Number of nights } \\
\text { surveyed }\end{array}$ & 16 & 16 & 5 & 13 & 7 & 10 & 9 & 8 & 13 & 11 \\
\hline $\begin{array}{l}\text { Date range over } \\
\text { which sample } \\
\text { collected }\end{array}$ & $\begin{array}{l}11 \text { May- } \\
31 \text { May }\end{array}$ & $\begin{array}{l}21 \text { Aug- } \\
5 \text { Sep }\end{array}$ & $\begin{array}{l}12 \text { May- } \\
18 \text { May }\end{array}$ & $\begin{array}{l}26 \text { Aug- } \\
7 \text { Sep }\end{array}$ & $\begin{array}{l}19 \text { May- } \\
26 \text { May }\end{array}$ & $\begin{array}{l}25 \mathrm{Aug}_{-} \\
3 \mathrm{Sep}\end{array}$ & $\begin{array}{l}19 \text { May- } \\
28 \text { May }\end{array}$ & $\begin{array}{l}24 \mathrm{Aug}_{-} \\
2 \mathrm{Sep}\end{array}$ & $\begin{array}{l}18 \text { May- } \\
30 \text { May }\end{array}$ & $\begin{array}{l}19 \mathrm{Aug}_{-} \\
29 \mathrm{Aug}\end{array}$ \\
\hline Hours surveyed & 97.4 & 119.4 & 24.8 & 119.1 & 27.0 & 43.4 & 54.5 & 73.2 & 91.6 & 93.6 \\
\hline Targets $/ \mathrm{hr}$ & 245.1 & 377.9 & 127.0 & 1140.0 & 793.6 & 2262.7 & 1014.1 & 1129.3 & 1797.7 & 915.3 \\
\hline
\end{tabular}

\section{Flow-assisted movement in relation to season}

Across the survey period the predominant wind vectors at the study site were generally to the northwest. The circular mean wind vector across all spring migration periods (2008-2012) was $355.25^{\circ}$ (rho $=0.65)$ and the circular mean wind vector in for the fall migration periods was $341.27^{\circ}$ ( $\left.r h o=0.74\right)$. The circular mean target track bearing for the spring migrants (all years combined) was $301.39^{\circ}$ $(r h o=0.45)$, while the circular mean target track bearing for the fall was $125.95^{\circ}$ ( $r h o=0.27$; Fig. 2 ). Because wind directionality was relatively consistent during both migration periods, most transit during the northward spring migration occurred during tailwind conditions, while southern migration in the fall is predominantly under headwind conditions. Indeed, flowassistance (wind profit) for migratory movement was higher in spring than fall $\left(F_{1,536}=358.34, P<0.0001\right.$; Fig. 3$)$, but did not differ within season based on operational phase of the wind installation (Operational Phase: $F_{1,536}=0.04, P=0.83$; Interaction between Season x Operational Phase: $F_{1,536}=2.18, P=0.14$ ).

Fig. 2. The averaged bearings of spring and fall migrants across the years 2008-2012 at the Dokie I Wind Energy Project in northeastern British Columbia, Canada.
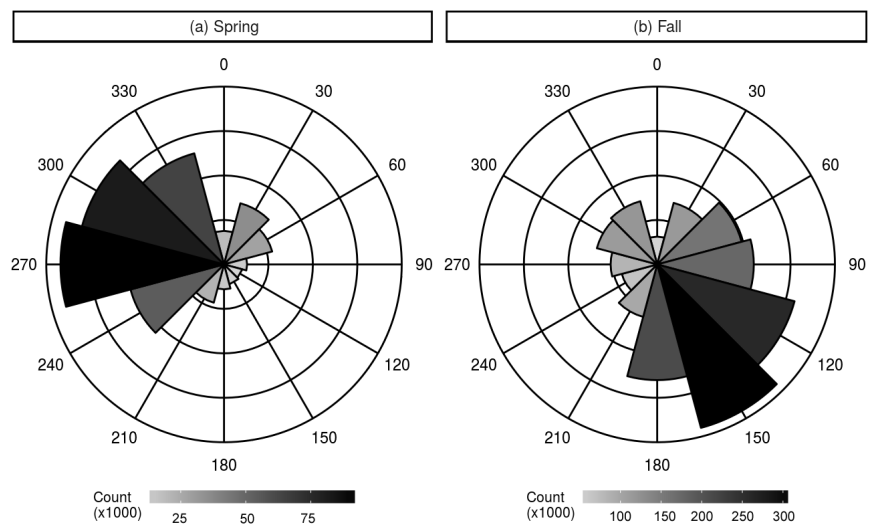

Fig. 3. Flow-assistance, a vector measure of the effect of wind direction and speed on the ability of birds to maintain their intended migratory direction and speed, was compared between the preoperational phases (2008-2010) and operational phases (2011-2012) at the Dokie I Wind Energy Project in northeast British Columbia. Data is partitioned into spring and fall migration. Positive values of flow assistance indicate wind direction and strength that would assist migrants in maintaining direction and airspeed, with values $\sim+20$ representing full and strong tail winds. Stronger negative values represent increasing impediments to maintain migratory direction and airspeed, with values of $\sim-20$ representing strong headwinds. Migrants in the spring gain positive flow-assistance, but this did not differ between preoperational and operational phases of the wind facility. Fall migrants had significantly lower flow-assistance than fall migrants, but this did not differ between preoperational vs operational phases.

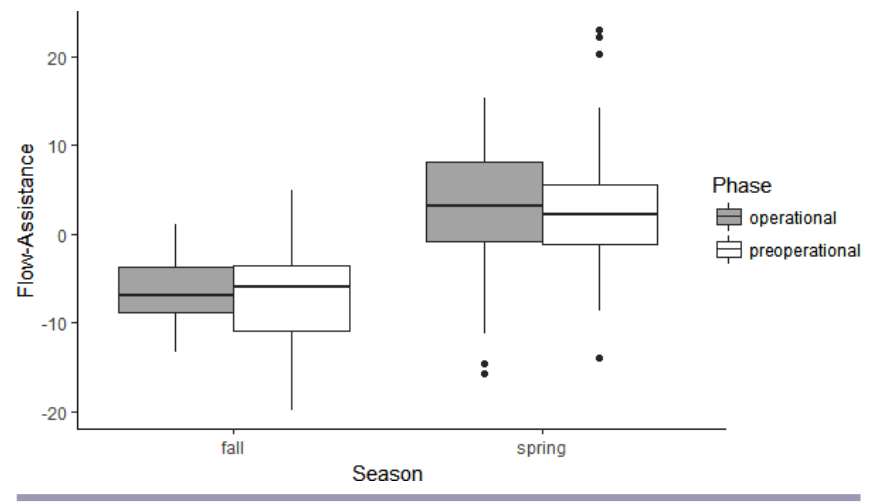

\section{Average heights of targets}

The altitude of targets detected during spring migrations were significantly lower during the preoperational phase relative to the operational phase (GAM model: Estimate $=-0.21 \pm 0.0034 \mathrm{SE}$, $t=-63.06, P<0.0001$; Fig. 4). The median altitude during the preoperational years was $360 \mathrm{~m} \mathrm{agl}$, whereas during the two operational years it was $453 \mathrm{~m}$ agl. The approximate estimate of 
the smoothing term explaining variation in altitudes across time of night was also significant $\left(e d f=5.92 F=197.8 P<0.0001, R^{2}\right.$ $($ adj $)=0.029$ Deviance explained $=2.2 \%$ ); there was a slight rise in altitudes from the first hours after sunset which then stabilized and remained steady for the remainder of the night. There appeared to be a similar pattern between preoperational and operational phases of the wind installation, but shifted upward in the operational phase (Fig. 4).

Fig. 4. Variation in the distribution of altitudes of nocturnal migrants by hour of night (standardized as hours after sunset) during the preoperational phase (2008-2010) and operational phases (2011-2012) in spring (a) and fall (b) at the Dokie I Wind Energy Project in northeast British Columbia. Heights during the operational period (white boxes and solid line) were significantly higher than heights recorded during the preoperational period (grey boxes and dashed lines) in both seasons. Lines represent the smoothed approximations from a general additive model on changes in height in relation to hours of migration. Length of the dawn-dusk period is two hours greater in fall than spring migratory period at the site.
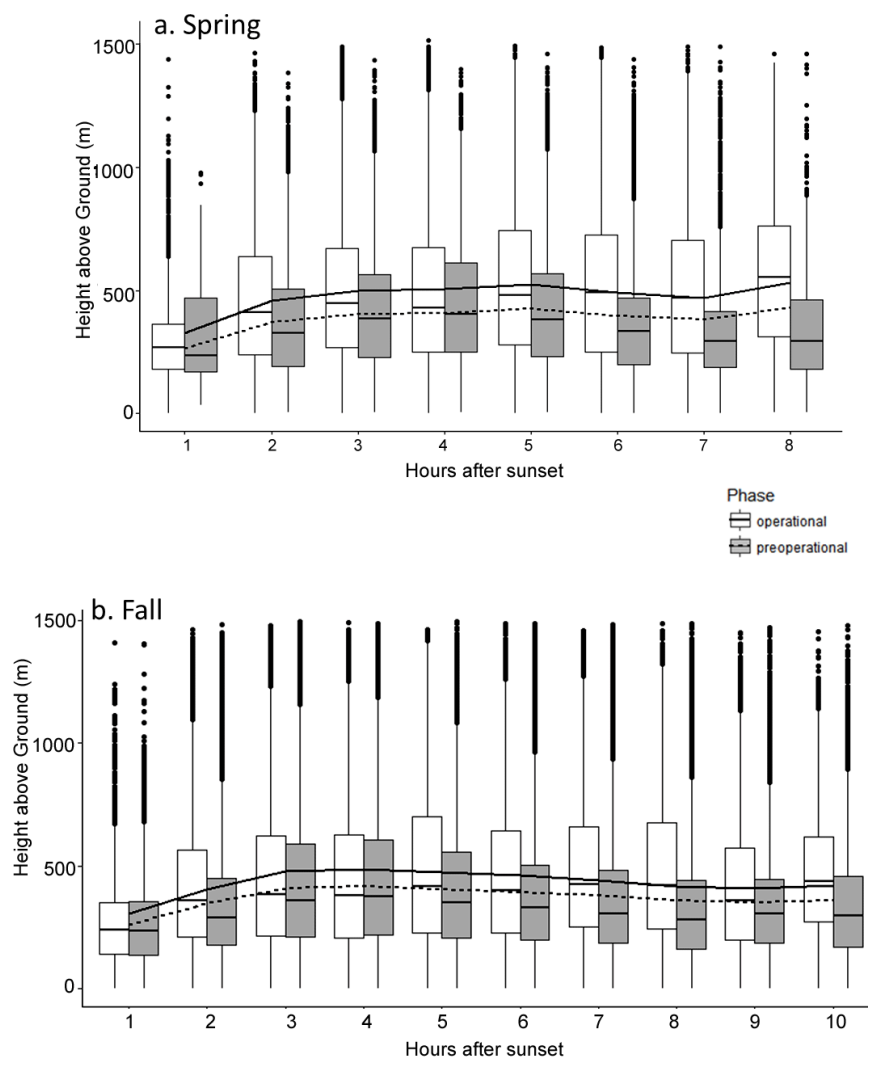

Similarly, the altitude of targets detected during fall migrations were also significantly lower during the preoperational phase ( median $=321 \mathrm{~m} \mathrm{agl})$ relative to the operational phase $($ median $=$ 389 (GAM model: Estimate $=-0.16 \pm 0.0021 \mathrm{SE}, t=-76.58, P<$ 0.0001 ; Fig. 4), and the smoothing term explaining variation in altitudes across time of night was also significant $(e d f=5.90 \mathrm{~F}=$ $1286.00, P<0.0001, R^{2}(a d j)=0.027$ Deviance explained $=2.4 \%$ ). As with spring migration, that altitudes of targets in the fall tended to be lowest early in the evening, increasing and then staying relatively stable across the remaining hours of tracking throughout the night (Fig. 4).

\section{Proportion of detected targets in the lowest altitude categories}

When controlling for the effects of individual nights as a random effect, there was no difference in the number of targets detected in the lowest height category $(0-150 \mathrm{~m}$ agl) relative to the other altitudes because of either season (binomial GLM: $z=0.12, P=$ $0.90)$ or operational phase $(z=1.17, P=0.24)$, nor was there an interaction between these variables (season $\mathrm{x}$ operational phase: $z$ $=-0.083, P=0.93$; Fig. 5). However, the number of birds in the second altitude category $(151-300 \mathrm{~m} \mathrm{agl})$ relative to other height categories did differ by operational phase of the wind installation $(z=2.13, P=0.033)$, but not by season $(z=-1.45, P=0.15)$; the proportion of birds in this altitude category decreased during the operational phase of the study relative to the preoperational phase, and the effect was similar in both spring and fall migration (Fig. 5). There was no interaction effect between season and operational phase in the number of targets detected in the 151-300 m agl altitude category $(z=1.20, P=0.23)$.

Fig. 5. The proportion of detected targets for both fall and spring migration periods, separated by operational phase of the wind installation. There was no difference between seasons or operational phase in the proportion of detected targets in the lowest altitude category (0-150 m above ground level [agl]), which would correspond to the turbine locations. However, in the next height category $(151-300 \mathrm{~m} \mathrm{agl})$, the proportion of birds dropped significantly in the years the turbines were operational relative to preoperational years, and this effect was similar in both seasons.

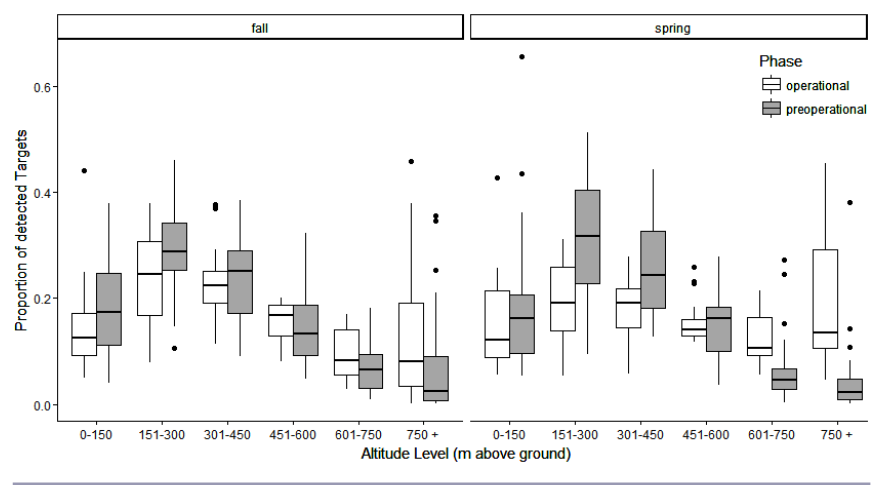

\section{DISCUSSION}

The number of nocturnal migrants per hour detected around the Dokie I Wind Energy facility varied by season, with generally higher passage rates in the fall than in the spring on both the vertical and horizontal radars. This is expected because both adult and juvenile birds are moving during the postbreeding season in the fall (Harmata et al. 2000, Otter et al. 2014). Further, some fall migrants may have been bats, which are more prominent in the fall migration (Kunz et al. 2007). The fall migratory season, however, had less favorable winds that provided much lower flow-assistance to migrants than occurred in the spring. One response to the 
difference in flow-assistance between seasons we may have expected would be for birds to fly at different altitudes (e.g., Kemp et al. 2013) but we found that the vertical distribution of migrants was similar between seasons in the preoperational surveys, either measured in median altitudes or proportions of detected migrants in each $150 \mathrm{~m}$ height category. Where we did see shifts in altitude was in response to operational phase of the turbines, but the effect was largely parallel in either season despite the seasonal differences in flow-assistance.

If migrants were adjusting height to avoid collisions with operational wind turbines, we expected to see a reduction in the number of targets at the lowest height category $(0-150 \mathrm{~m}$ agl, cooccurring with the turbines) during operational phases of the wind farm. The number of targets detected in this lowest height categories ( $0-150 \mathrm{~m} \mathrm{agl})$ was, however, not affected by operational phase. Yet, in preoperational years, the highest proportion of migrants were found not in this lowest height category, but in the airspace immediately above (151-300m agl). During the years in which turbines were operational, there was a significant reduction in the proportion of targets detected in this airspace, instead appearing to shift into higher height categories (Fig 5). This was also reflected in a higher median hourly altitude of migrants tracked during the operational period, which occurred in both seasons. As altitudes were increased by approximately $70 \mathrm{~m}$ (fall) to $90 \mathrm{~m}$ (spring) upwards, this suggests that nocturnal migrants may respond to the presence of the wind project by adjusting their altitudes.

The wind turbines in our study site were $120 \mathrm{~m}$ tall and during the operational phase of the study there were still migrants moving within this airspace. However, this constituted less than $20 \%$ of the detected targets using the airspace around the wind turbines even under preoperational conditions. Although there was no reduction in the proportion of targets within this airspace when turbines were operational, our vertical radar could not resolve whether those targets were making adjustments in their flight paths to move in the airspace between turbines. Regardless, our data do support for microscale adjustments in migratory behavior because birds increased flight altitude by $70-90 \mathrm{~m}$ in response to the presence of wind turbines. Because the median heights of nocturnal migrants were $200 \mathrm{~m}$ or more above turbine heights $(125 \mathrm{~m})$ during preoperational surveys in either season, this suggested the impact of development from this particular wind energy project was low.

One caveat to this assessment is that our radar surveys were conducted on clear nights. This is a constraint of utilizing X-band radars; because these utilize wavelengths capable of resolving passerine-sized targets, they also resolve water vapour (fog, clouds, rain) and this precludes accurately surveying during precipitation and dense fog. However, these periods have been implicated as potentially high-risk weather conditions for bird collisions with wind turbines (Marques et al. 2014). However, we feel that the data from our studies likely reflects a low collision potential at this particular installation, because our low predicted collision rates are consistent with postconstruction carcass searching on the site. These searches yielded very low estimated collision rates of $<0.01 \%$ (Stantec Consulting Ltd. 2012a, $b$, Otter et al. 2014). Further, those carcass search estimates were conducted almost daily from March through October in the two operational years, covering a greater period and varying weather conditions than were possible with this radar tracking study. Thus, although adjustments to altitude during the operational phase were minor, our results and those of carcass searches suggest that turbines at this site are detected and minor altitudinal adjustments are made that would serve to further reduce already low collision risk, similar to flight adjustment patterns of diurnal migrants at this same installation (Johnston et al. 2014). The low collision rates at this facility may reflect its location; the site appears to be situated on a migratory route, but does not appear to constitute a major stop-over site or wintering ground, and is no more extensively used as a breeding site than other areas in the region. Most detected nocturnal and diurnal migrants appear to be simply moving through the site.

Avoidance rates of nocturnally migrating species toward wind turbines have not been extensively studied, but conservative estimates of $98 \%$ to $99 \%$ avoidance have been used in collisionrisk models (Chamberlain et al. 2006, Liechti et al. 2013). Nocturnal migrants primarily comprise passerine species that are relatively abundant and widespread so subtle changes in avoidance rates can have large implications on the accuracy of collision-risk models (Chamberlain et al. 2006). Microscale avoidance at our study site seems restricted to small adjustments to increase altitude during the operational phase of the wind installation, however, quantifying the degree of microscale avoidance remains a challenge because some migrants are flying below the heights of turbines and may be taking evasive actions at individual turbines. Preliminary results from night vision cameras set up at and between wind turbines in the study site suggested that there may have been a slight decrease in the number birds moving near turbines compared to the number of birds detected between turbines, which would influence avoidance rates (Walsh 2012).

In conclusion, at the microscale level, nocturnal migrants showed some indications of adjusting their movements around the wind energy facility during the operational period, yet their typical migratory behavior was also not placing them in collision risk situations for the most part. Subtle adjustments in altitude may be occurring, which would further reduce collision risk at the wind project level. Changes at the macroscale level may be occurring to avoid wind energy facilities, although we found little evidence suggesting fewer detected targets during migratory seasons during the operational phase of the installation.

\section{Management implications}

The radar data from this study showed that there was high nocturnal migration movement through the northeast British Columbia region in both spring and fall, providing context to the number of migrants potentially exposed to collision-risk situations (Otter et al. 2014). At the Dokie I Wind Energy Project, during two years of postconstruction mortality monitoring an estimate of 35 fatalities (birds and bats combined) were found during the periods when we were conducting radar surveys (Otter et al. 2014). After correcting these numbers for searcher efficiency and scavenger impact, the estimated annual mortality rate was $<$ $0.01 \%$ of known migrants (Otter et al. 2014), but this estimate was based solely on the total number of detected radar tracks during the operational years. It did not account for the vertical stratification of migrants, and the data in the current manuscript 
to suggest that migrants may adjust altitude in response to operational turbines. The detailed data on nocturnal migration could suggest that avoidance behavior in postconstruction can reduce estimates of collision risk that were based on preconstruction monitoring. These avoidance rates may, however, reflect regional variation in collision risk, so we recommend using similar methodology to detail passage rates in relation to mortality rates in postconstruction years to derive accurate, local collision risk estimates. Further, avoidance behavior may vary by avian guild, and the way in which species utilize the site. The greatest impacts of wind installations on avian populations appears to coincide with placement of turbines in important breeding sites, particularly when placed between nesting and feeding grounds (e.g., Stienen et al. 2008, Dahl et al. 2013), migratory bottlenecks, stop-over or wintering sites (Drewitt and Langston 2006). Thus, siting of wind developments in relation to avian use and behavior within sites should likely be the first consideration in management (Marques et al. 2014).

Responses to this article can be read online at: http://www.ace-eco.org/issues/responses.php/1046

\section{Acknowledgments:}

We thank the many people involved in the collection of the radar data including D. Walsh, N. Johnston, A. Pomeroy, and M. Schmidt, as well as J. Brzustowski and P. Taylor for their assistance with the program radR. H. Russell, M. Laziner, and S. Yu provided technical support on the operation of the radar digital interface system. Stefanie LaZerte was instrumental in helping with the R coding for data management and analysis. We also thank Rob Bryce for operating his Easy Star II Airplane and Greg Sanders at Tech Helicopters for use of the Robertson 222 in radar calibration. The Dokie General Partnership, EarthFirst Canada Inc., and Stantec provided logistic and financial support. Additional funding support was provided by the Natural Sciences and Engineering Research Council (NSERC) Strategic Projects Grants, Special Opportunities Grants, and Collaborative Research and Development Grants programs, Environment Canada Grant-in-Aid of Research, UNBC, and Aboriginal Affairs and Northern Development Canada's Northern Scientific Training Program. We acknowledge and thank the West Moberly First Nation for supporting our research in their traditional territory and $H$. Schmaljohann, F. Liechti, and an anonymous reviewer for their comments on earlier drafts of the manuscript.

\section{LITERATURE CITED}

Able, K. P. 2004. Birds on the move: flight and migration. Cornell Lab of Ornithology, Ithaca, New York, in association with Princeton University Press, Princeton, New Jersey, USA.

Agostinelli, C. 2009. Circular Statistics, from "Topics in circular Statistics" (2001) S. Rao Jammalamadaka and A. SenGupta, World Scientific. R Foundation for Statistical Computing, Vienna, Austria.

Bates, D., M. Mächler, B. Bolker, and S. Walker. 2015. Fitting linear mixed-effects models using lme4. Journal of Statistical Software 67:1-48. http://dx.doi.org/10.18637/jss.v067.i01
Bruderer, B. 1997. The study of bird migration by radar - Part 2: Major achievements. Naturwissenschaften 84:45-54. http://dx. doi.org/10.1007/s001140050348

Bruderer, B., and A. Boldt. 2001. Flight characteristics of birds: I. radar measurements of speed. Ibis 143:178-204. http://dx.doi. org/10.1111/j.1474-919X.2001.tb04475.X

Chamberlain, D. E., M. R. Rehfisch, A. D. Fox, M. Desholm, and S. J. Anthony. 2006. The effect of avoidance rates on bird mortality predictions made by wind turbine collision risk models. Ibis 148:198-202. http://dx.doi.org/10.1111/j.1474-919X.2006.00507. $\mathrm{x}$

Dahl, E. L., R. May, P. L. Hoel, K. Bevanger, H. C. Pedersen, E. Røskaft, and B. G. Stokke. 2013. White-tailed eagles (Haliaeetus albicilla) at the Smøla wind-power plant, Central Norway, lack behavioral flight responses to wind turbines. Wildlife Society Bulletin 37:66-74. http://dx.doi.org/10.1002/wsb.258

Dokter, A. M., F. Liechti, H. Stark, L. Delobbe, P. Tabary, and I. Holleman. 2011. Bird migration flight altitudes studied by a network of operational weather radars. Journal of the Royal Society Interface 8:30-43. http://dx.doi.org/10.1098/rsif.2010.0116

Dokter, A. M., J. Shamoun-Baranes, M. U. Kemp, S. Tijm, and I. Holleman. 2013. High altitude migration at temperate latitudes: a synoptic perspective on wind assistance. PLOS ONE 8(1): e523000. http://dx.doi.org/10.1371/journal.pone.0052300

Drewitt, A. L., and R. H. W. Langston. 2006. Assessing the impacts of wind farms on birds. Ibis 148:29-42. http://dx.doi. org/10.1111/j.1474-919X.2006.00516.x

Erickson, W. P., M. M. Wolfe, K. J. Bay, D. H. Johnson, and J. L. Gehring. 2014. A comprehensive analysis of small-passerine fatalities from collisions with turbines at wind energy facilities. PLoS ONE 9(9):e107491. http://dx.doi.org/10.1371/journal. pone. 0107491

Gauthreaux, S. A. 1991. The flight behavior of migrating birds in changing wind fields: radar and visual analyses. Integrative \& Comparative Biology 31:187-204. http://dx.doi.org/10.1093/ $\mathrm{icb} / 31.1 .187$

Harmata, A. R., K. M. Podruzky, J. R. Zelenak, and M. L. Morrison. 2000. Passage rates and timing of bird migration in Montana. American Midland Naturalist 143:30-40. http://dx.doi. org/10.1674/0003-0031(2000)143[0030:PRATOB]2.0.CO;2

Jacques Whitford AXYS Ltd. 2006. Wildlife monitoring report Fall 2006 - Dokie Wind Energy Project. Jacques Whitford AXYS Ltd., Burnaby, British Columbia, Canada.

Johnson, G. D., W. P. Erickson, M. D. Strickland, M. F. Shepard, D. A. Shepard, and S. A. Sarappo. 2002. Collision mortality of local and migrant birds at a large-scale wind-power development on Buffalo Ridge, Minnesota. Wildlife Society Bulletin 30:879-887.

Johnston, N. N., J. E. Bradley, and K. A. Otter. 2014. Increased flight altitudes among migrating Golden Eagles suggest turbine avoidance at a Rocky Mountain wind installation. PLOS ONE 9 (3):e93030. http://dx.doi.org/10.1371/journal.pone.0093030

Kemp, M. U., J. Shamoun-Baranes, A. M. Dokter, E. van Loon, and W. Bouten. 2013. The influence of weather on the flight 
altitude of nocturnal migrants in mid-latitudes. Ibis 155:734-749. http://dx.doi.org/10.1111/ibi.12064

Kemp, M. U., J. Shamoun-Baranes, E. van Loon, J. D. McLaren, A. M. Dokter, and W. Bouten. 2012. Quantifying flow-assistance and implications for movement research. Journal of Theoretical Biology 308:56-67. http://dx.doi.org/10.1016/j.jtbi.2012.05.026

Klaassen, M., B. J. Hoye, B. A. Nolet, and W. A. Buttemer. 2012. Ecophysiology of avian migration in the face of current global hazards. Philiosophical Transactions of the Royal Society B 367:1719-1732. http://dx.doi.org/10.1098/rstb.2012.0008

Kunz, T. H., E. B. Arnett, B. M. Cooper, W. P. Erickson, R. P. Larkin, T. J. Mabee, M. L. Morrison, M. D. Strickland, and J. M. Szewzak. 2007. Assessing impacts of wind-energy development on nocturnally active birds and bats: a guidance document. Journal of Wildlife Management 71:2449-2486. http://dx.doi. org/10.2193/2007-270

Kuvlesky, W. P., L. A. Brennan, M. L. Morrison, K. K. Boydston, B. M. Ballard, and F. C. Bryant. 2007. Wind energy development and wildlife conservation: challenges and opportunities. Journal of Wildlife Management 71:2487-2498. http://dx.doi.org/10.2193/2007-248

Liechti, F., J. Guélat, and S. Komenda-Zehnder. 2013. Modelling the spatial concentrations of bird migration to assess conflicts with wind turbines. Biological Conservation 162:24-32. http://dx. doi.org/10.1016/j.biocon.2013.03.018

Liechti, F., and E. Schaller. 1999. The use of low-level jets by migrating birds. Naturwissenschaften 86:549-551. http://dx.doi. org/10.1007/s001140050673

Liechti, F., and H. Schmaljohann. 2007. Wind-governed flight altitudes of nocturnal spring migrants over the Sahara governed by wind. Ostrich 78:337-341. http://dx.doi.org/10.2989/ OSTRICH.2007.78.2.35.115

Longcore, T., C. Rich, and S. A. Gauthreaux. 2008. Height, guy wires, and steady burning lights increase hazard of communication towers to nocturnal migrants: a review and metaanalysis. Auk 125:485-492. http://dx.doi.org/10.1525/auk.2008.06253

Loss, S. R., T. Will, and P. P. Marra. 2013. Estimates of bird collision mortality at wind facilities in the contiguous United States. Biological Conservation 168:201-209. http://dx.doi. org/10.1016/j.biocon.2013.10.007

Mabee, T. J., B. A. Cooper, J. H. Plissner, and D. P. Young. 2006. Nocturnal bird migration over an Appalachian ridge at a proposed wind power project. Wildlife Society Bulletin 34:682-690. http://dx.doi.org/10.2193/0091-7648(2006)34[682:NBMOAA] 2.0. $\mathrm{CO} ; 2$

Mabey, S. E. S. 2004. Migration ecology: issues of scale and behavior. Pages 66-68 in S. Savitt Schwartz, editor. Proceedings of the Wind Energy and Birds/Bats Workshop: Understanding and Resolving Bird and Bat Impacts. Washington, D.C. May 18-19. RESOLVE Inc., Washington, D.C., USA.

Marques, A. T., H. Batalha, S. Rodrigues, H. Costa, M. J. R. Pereira, C. Fonseca, M. Mascarenhas, and J. Bernardino. 2014. Understanding bird collisions at wind farms: an updated review on the causes and possible mitigation strategies. Biological Conservation 179:40-52. http://dx.doi.org/10.1016/j.biocon.2014.08.017
Otter, K. A., M. I. Hartley, M. V. d'Entremont, N. N. Johnston, D. Walsh, J. E. Bradley, M. Willie, and A. C. Pomeroy. 2014. Avian movement at the Dokie I Wind Energy Project 2008-2012: analysis of potential conflict between wind development and avian migration in the northern Rocky Mountains. Natural Resources and Environmental Studies Institute (NRESi) Technical Report \#1. University of Northern British Columbia, Prince George, British Columbia, Canada. [online] URL: http://www.unbc.ca/nresinstitute/technical-report-series

Pocewicz, A., W. A. Estes-Zumpf, M. D. Andersen, H. E. Copeland, D. A. Keinath, and H. R. Griscom. 2013. Modelling the distribution of migratory bird stopovers to inform landscapescale siting of wind development. PLoS ONE 8(10):e75363. http://dx.doi.org/10.1371/journal.pone.0075363

Pomeroy, A. C., P. Thomas, C. Morcos, A. Labrosse, J. Preston, C. Bryden, M. V. d'Entremont, and K. A. Otter. 2007. Wildlife monitoring report 2007 - Dokie and Wartenbe Wind Energy Projects. Technical Data Report for EarthFirst Canada Inc. Jacques Whitford AXYS Ltd., Burnaby, British Columbia and the Center for Wind Energy and the Environment, University of Northern British Columbia, Prince George, British Columbia, Canada.

R Development Core Team. 2017. $R$ A language and environment for statistical computing. R Foundation for Statistical Computing, Vienna, Austria. http://www.R-project.org

Schmaljohann, H., F. Liechti, E. Bächler, T. Steuri, and B. Bruderer. 2008. Quantification of bird migration by radar - a detection probability problem. Ibis 150:342-355. http://dx.doi. org/10.1111/j.1474-919X.2007.00797.X

Schmaljohann, H., F. Liechti, and B. Bruderer. 2009. TransSahara migrants select flight altitudes to minimize energy costs rather than water loss. Behavioral Ecology and Sociobiology 63:1609-1619. http://dx.doi.org/10.1007/s00265-009-0758-x

Stantec Consulting Ltd. 2012a. Dokie Wind Energy Project 2011 operational wildlife monitoring report. Stantec Consulting Ltd., Burnaby, British Columbia, Canada.

Stantec Consulting Ltd. 2012b. Dokie Wind Energy Project 2012 operational wildlife monitoring report. Stantec Consulting Ltd., Burnaby, British Columbia, Canada.

Stienen, E. W. M., W. Courtens, J. Everaert, and M. Van de Walle. 2008. Sex-biased mortality of Common Terns in wind farm collisions. Condor 110:154-157. http://dx.doi.org/10.1525/ cond.2008.110.1.154

Taylor, P. D., J. M. Brzustowski, C. Matkovich, M. L. Peckford, and D. Wilson. 2010. radR: an open-source platform for acquiring and analysing data on biological targets observed by surveillance radar. BMC Ecology 10:22. http://dx.doi.org/10.1186/1472-6785-10-22

Walsh, D. A. 2012. A technique for avian nocturnal migration research: determining flight pattern of local nocturnal migrants around pre-operation wind turbines. Thesis. University of Northern British Columbia, Prince George, British Columbia, Canada.

Wickham, H. 2009. ggplot2: elegant graphics for data analysis. Springer, New York, New York, USA. 
Wood, S. N. 2006. Generalized additive models: an introduction with $R$. Chapman and Hall/CRC, Boca Raton, Florida, USA.

Zimmerling, J. R., A. C. Pomeroy, M. V. d'Entremont, and C. M. Francis. 2013. Canadian estimate of bird mortality due to collisions and direct habitat loss associated with wind turbine development. Avian Conservation and Ecology 8(2):10. http://dx. doi.org/10.5751/ACE-00609-080210 


\section{Appendix 1. Analytical protocols for the detection and autoextraction of aerial vertebrate targets from digital radar signals at a wind energy project.}

The objective of this supplementary material is to outline the techniques used to test and calibrate the final bird-tracking radar settings used in the primary study. The relative locations and set up of field deployment is described in the main study. Here we focus on the equipment used and in testing the capacity of this system in acquiring and autotracking targets, and setting used to minimize potential tracking of non-interest targets (insects).

\section{Equipment}

Radars used to track nocturnal migrants were two Furuno 1954C X-band marine radar units (12kW, 9,000 MHz, 1.83 m open array antennas - Furuno Electric Company Ltd. Miki Japan), one radar set in the horizontally-rotating surveillance position and the second unit was set in the vertical-rotating position to track heights of targets. The main beam of the horizontal radar unit scanned an $\operatorname{arc}$ of $22^{\circ}$ (vertical) with a beam width of $1.9^{\circ}$ (horizontal), rotating $360^{\circ}$ every 2.5 secs. Likewise, the main beam of the vertical radar unit was $22^{\circ}$ (horizontal) in width with an arc of $1.9^{\circ}$ (vertical). For the horizontal radar unit, the wave guide was tilted to $25^{\circ}$ above horizontal to further reduce the amount of ground clutter and increase the amount of airspace surveyed (Harper et al. 2004). Both radar units were set on short-pulse length (80 ns at pulse repetition frequency $[\mathrm{PRF}]=2100 \mathrm{~Hz}$ ) with a range of $1.5 \mathrm{~km}$. Rain and sea clutter suppression algorithms were turned off. The gain scale on the radars ranged from 0 to 100 and we used a setting of 76 , which was the highest setting, determined during radar tuning, which maximized the information returned from targets while reducing the amount of radar noise. With the added influence of side lobes, this created a detection zone of approximately $500 \mathrm{~m}$ depth throughout the $1.5 \mathrm{~km}$ range, which was verified independently by recording movements of a training helicopter (Robertson 
R22 - Tech Helicopters Ltd.) and small remote model aircraft (Easy Star II Airplane Kit; 1.3 m wingspan; Model MPU214260 - Multiplex Modelsport USA) mounted with altimeters and GPS units that were flown at stratified altitudes across a flight grid within the $1.5 \mathrm{~km}$ detection zone (M.I. Hartley, K.A. Otter, unpublished data).

Each radar unit was equipped with an electronic interface system, including a signal digitizer (XIR3000B) and radar software (WinHorizon Version 1.5.0.13 - Russell Technologies Inc., North Vancouver, BC; http://www.russelltechnologies.ca/). The XIR3000B is an 8-bit digitization card that operated in slave mode whereby it transcribed the analog signals being passed from the transceiver to the radar master and digitized the return signals: video, trigger, ships heading marker and azimuth information. WinHorizon is a multi-purpose automatic radar plotting aid that offered a raster-scan radar image with a 4096 scan line resolution display. The digitized raw radar signals from each scan were saved as individual files that represented one 2.5 sec scan of the radar and were automatically saved into separate electronic folders for each data recording session. From the spring of 2008 to the fall of 2012, we recorded over $800 \mathrm{hrs}$ from the horizontal radar and $744 \mathrm{hrs}$ of data from the vertical radar.

\section{Target detection and tracking}

We attempted to discriminate aerial vertebrates from non-vertebrates (i.e., insects, ground clutter) and hereafter refer to each as "true targets" and "false targets", respectively. In our data, it was likely that aerial vertebrate targets were predominantly birds since monitoring of bat activity in 2008 to 2010 indicated relatively low occurrences of bats (Jacques Whitford AXYS Ltd. 2009, Pomeroy et al. 2010), although these likely comprise a small number of the detected targets, particularly in fall migration. We compared the capacity to detect and track true targets 
from the radar using three techniques: Manual detection, Auto detection and Real-time detection. These techniques are sequentially compared below.

\section{Comparison of Manual detection vs Auto detection}

Manual-detection was conducted on recorded twenty-nine 15-minute segments of digitallyrecorded radar data, taken from spring migration data between 2008 and 2011. We selected the 15-min periods of radar data from nights where no rain was present and spanning the date ranges within each year; and from these, we selected the sampled periods to balance the represented hours of the night in which data was collected (dusk to dawn). Manual-detection of each sample period of radar data was completed using WinHorizon software (Russell Technologies) where imagery could be paused and replayed. This allowed us to manually count the exact number of recorded true targets, summated on a per minute basis. True targets were discriminated from false targets based on relative flight direction and speed, aided with the trails function on moving targets and the high-colour display in WinHorizon. The total number of true targets recorded using the Manual-detection method for the 15-min periods ranged from 6 to 887, with a median value of 153 targets. We used this median value as the cut-off between less intense movements and more intense movements to correlate the accuracy of the Auto detection method (described below). Each target took approximately one minute to process using the Manual detection method, so the time required to manually-score the 15 -min periods ranged from 15 min to 14.75 hrs, depending upon the density of migrants within the recordings.

To extract target information from the digitally-recorded radar data using the Auto detection method, we employed the open-source analysis platform radR (Version 2.5.1, Taylor et al. 
2010), which is written in the $\mathrm{R}$ statistical programming language ( $\mathrm{R}$ Development Core Team 2014). We used the XIR3000arch plugin in radR to playback the files originally recorded in WinHorizon. radR has built in algorithms to detect and track only moving targets and ignores successive returns from stationary clutter. The detection and tracking of targets in radR was summarized as a two-step process whereby the true targets (blips) were initially identified with the blip filtering plugin and were then tracked with the tracker plugin.

The blip filtering plugin is a target-finding algorithm with user-defined variables that can be set to filter true targets within the radar signal. Each digital scan gets processed as a matrix of integers comprised of pulses (columns) and range cells (rows). The columns in the matrix are uniformly spaced around the radar's rotational plane (e.g., $0^{\circ}$ through $360^{\circ}$ azimuth) and represent the amount of energy reflected back from a target at increasing distance from the radar. Each row in the matrix corresponds to the energy received from a given range cell, while the radar was pointed at a particular direction. Each point in the matrix is known as a "sample" that represents the strength of the radar echo from a single pulse for a given range cell. radR uses a specified number of learning scans to compute a background intensity score for each sample across the scan, based on user-defined threshold values. An intensity score for each subsequent sample in the remaining scans was computed relative to the background score and groups of samples that exceeded the user-defined threshold were amalgamated into blips. WinHorizon software increases image resolution to 4096 pulses per scan, therefore, each sample had a value between 0 and 4096. 
The tracker plugin is based on a multiframe correspondence (MFC) algorithm (Shafique and Shah 2005) that builds active tracks by matching targets from two scans, based upon distance, velocity and blip characteristics (e.g., number of samples, area). When the third scan occurs, the algorithm predicts where that target will be, based on matching targets of similar characteristics and trajectories from the first two scans. As with blip filtering, several user-defined variables are set in the MFC algorithm and within the tracker plugin controls. For detailed explanations of the blip filtering and tracker plugins refer to Taylor et al. (2010).

We determined through preliminary testing of the radar data and consultations with the radR design team that adjustment to four key variables among the blip filtering and tracker plugins resulted in the greatest variability among the detection and tracking of true targets (J. Brzustowski, pers. comm.; Table S1). To determine the minimal values for each of these four variables for testing we examined radR outputs of known avian targets collected from paired radar and visual monitoring conducted at various airports in British Columbia (M. d'Entremont, unpublished data). We made visual observations of small birds (e.g., passerines), medium-sized birds (e.g., waterfowl, gulls and crow) and large birds (e.g., eagles) at varying distances within the radar detection field. We cross-referenced the visual observation data with the radR output and the average values for the various variables were used to set lower limits for testing. Each variable tested is described in Table S1, along with the values for that variable tested. 
Table A1.1. Variables adjusted within radR for autodetection and tracking of avian targets from radar recorded with the XIR3000B signal processor. Variation in the tested value for blip filtering is due to upgrades with the WinHorizon software from 1024 to 4096 scan lines in 2010.

\begin{tabular}{|c|c|c|c|}
\hline Plugin & Variable & Description & Tested Value \\
\hline Blip filtering & min blip samples & $\begin{array}{l}\text { The minimum number of samples } \\
\text { in a patch of hot targets. }\end{array}$ & $\begin{array}{c}7,8,9(2008-2009) \\
10,15,20(2010-2011)\end{array}$ \\
\hline Tracker & $\begin{array}{l}\text { minimum number } \\
\text { of blips required for } \\
\text { a track }\end{array}$ & $\begin{array}{l}\text { If a track does not meet the } \\
\text { minimum number of blips required } \\
\text { it is discarded. Smaller values } \\
\text { increase potential for including } \\
\text { false tracks, while larger values } \\
\text { potentially exclude true targets } \\
\text { with short trajectories }\end{array}$ & 4,5 \\
\hline Tracker & $\begin{array}{l}\text { number of scans to } \\
\text { backtrack over in } \\
\text { building tracks }\end{array}$ & $\begin{array}{l}\text { The algorithm will project } \\
\text { backwards a specific number of } \\
\text { scans when considering all possible } \\
\text { connections to the next blip. }\end{array}$ & 2,3 \\
\hline Tracker & $\begin{array}{l}\text { minimum gain for a } \\
\text { blip to join a track }\end{array}$ & $\begin{array}{l}\text { The gain function is used for } \\
\text { evaluating the match between blips } \\
\text { in an active track to a blip in the } \\
\text { next scan. }\end{array}$ & $10,15,20$ \\
\hline
\end{tabular}


To identify the best-suited values for the blip filtering and tracker variables to use for our radar data processing we subjected the 29 15-min recordings to autodetection using radR. Each 15-min sample was processed under the 36 different permutations of the blip filtering and tracker variables (every combination of tested values in Table S1) for a total of 1044 individual outputs. Using the autodetection method in radR, each 15-min sample period took less than 1 min to be processed. We fitted a linear regression separately for each of the 36 trials using the number of targets detected from the Manually-detection method as the independent variable and the number of targets detected using the autodetection method as the dependent variable to identify which combination of blip-filtering and tracker variables provided the best relationship between autodetection method and the actual known targets from the Manual-detection method. Statistical analysis was completed using Statistica Version 12 (Statsoft Inc. 2014).

Using the range of tested values for blip filtering and tracker processing in radR, we ranked the various permutations of values based on the $\mathrm{R}^{2}$ relationship between the number of targets that were tracked using Manual-detection versus the number of targets that were tracked using the autodetection method, and used this to identify the best combination of radR settings for autodetection and tracking of data. The best permutation $\left(\mathrm{R}^{2}=0.94\right)$ had a "min blip samples" value of 9 for the 2008 and 2009 data and a value of 20 for the 2010 and 2011 data. The other variables of the best permutation included a "minimum number of blips required for a track" value of 4; a "number of scans to backtrack over in building tracks" value of 2 and a "minimum gain for a blip to join a track" value of 20 (intercept $=-61.38$, slope $=1.56$, Fig. S1). 


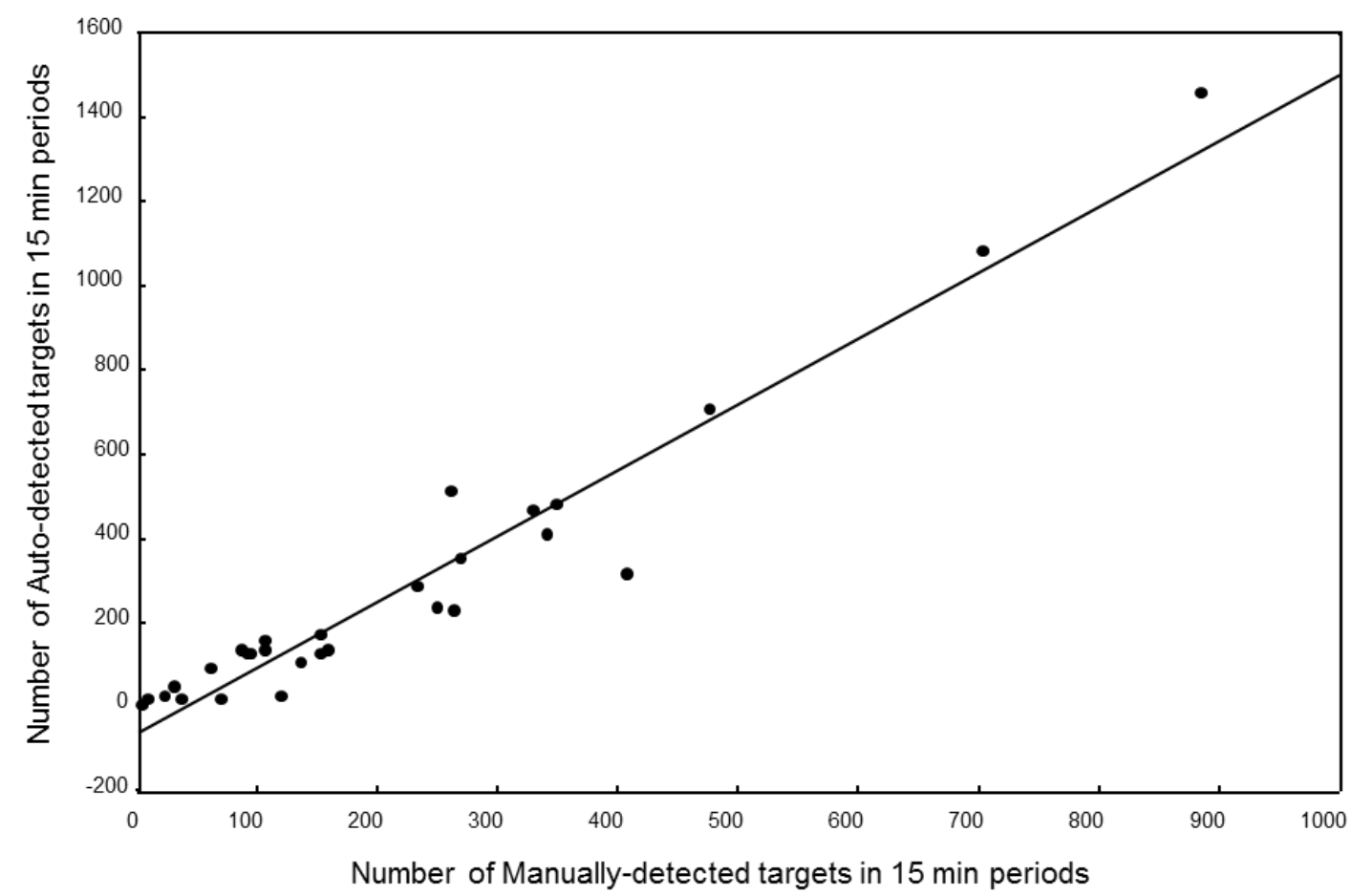

Fig. A1.1. Relationship between the estimated number of targets detected from 29 15-min sample periods of radar data processed in with the Autodetection method compared to the number of nocturnal migrants identified using the Manual-detection method of the same data. Estimated numbers were established through autotracking functions in radR using the using the highest-performing combination of values for blip filtering and tracking tested $\left(R^{2}=0.94\right.$, intercept $=-61.38$, slope $=1.56$ ). All data were collected at the Dokie I Wind Energy Project from 2008 to 2011.

We compared the radR output for the 15 min periods where movement was less intense $(<153$ targets/15 min) to those where movement was more intense (>153 targets/15 min). In both instances, the protocol had similar and very strong relationship between number of Manuallydetected targets and the number of autodetected targets (higher-intensity movement periods: $R^{2}=$ 
0.93, $F_{1,13}=83.5, P<0.001, n=14:$ lower-intensity movement periods: $R^{2}=0.89 ; F_{1,12}=47.6$, $P<0.001, n=13)$.

\section{Comparison of Autodetection vs Real-Time detection}

Real-time detection entailed direct observation/recording of targets from the radar monitor in the field, scoring targets as they moved across the screen. This mimicked traditional field practice in radar ornithology associated with wind farms, of scoring a non-recorded analog image, without the capacity to pause or replay the imagery.

From 2008 to 2010, we had five observers record the nocturnal movement of migrants using the Real-time detection method as the radars were being operated on site, and simultaneous to digitizing radar imagery. Real-time detection was conducted in hourly segments, alternating between the horizontal and vertical radars, during the first four hours after sunset. The spatial location of true targets relative to the radar, including the distance and bearing of when each first appeared were transcribed directly from the radar monitor. Observers recorded the size and number of times each target appeared on the monitor and its distance and bearing when it last appeared on the monitor. These real-time detections in the field took 15 mins, the length of the recording period and a total of $72 \mathrm{hrs}$ of horizontal data and $67 \mathrm{hrs}$ of vertical data were analysed using the real-time detection method (during this same period over 405 hrs of horizontal data and over 385 hrs of vertical data were digitally recorded, including the subset of hours tracked in Real-time above).

To demonstrate the potential for additional information gathering afforded by the autodetection method, relative to Real-time detection method, we correlated the number of targets autotracked from 24 of the 15 -min periods used above to the number of targets recorded 
by observers using real-time detection in the field for the same time periods (Pomeroy et al. 2010). Overall, there was a $300 \%$ increase in the number of targets detected using the autodetection method compared to the number of targets using the real-time detection method in the field. In all but four of the 24 trials, there was a strong positive increase in target detection using autodetection compared to real-time detection, ranging from a $60.0 \%$ to $1035.6 \%$ increase. During less intense periods of movement ( $<153$ targets/15 min) the number of real-time detected targets were moderately correlated to the number of autodetected targets $(r=0.69, P<0.01, N=$ 17), although the number of targets autodetected was an average of $176 \%$ more than Real-time detected. Under periods of higher-intensity movement (>153 targets/15 $\mathrm{min}$ ), the number of autodetected was an average $563 \%$ higher than those recorded via Real-time detection, and the correlation between the number of real-time vs autodetected targets was lower $(r=0.40, P<$ $0.01, N=12)$.

\section{Filtering for non-vertebrate aerial targets}

Tracking of non-vertebrate aerial targets, such as insects or non-biological targets is a common issue that requires attention when processing radar data (Larkin 1991, Schmaljohann et al. 2008). We visually observed insects on nights when temperatures were $10^{\circ} \mathrm{C}$ or higher and wind speeds were low, and calibrated the intensity of high and low periods of insect presence from observations with an iGEN 20/20 night vision scope (iGEN, El Paso, TX, http://www.igen2020.com; D. Walsh, M. d'Entremont and K.A. Otter, unpublished data). In most cases these non-vertebrate aerial targets were moving at a lower speed relative to other targets on the radar monitor and were often moving in a different trajectory, mirroring passive movement with wind currents characteristic of insects (Cabrera-Cruz et al. 2013). These targets 
were recorded by the radar as oblong-shaped, low-intensity targets and were detected primarily at closer ranges (e.g., $<750 \mathrm{~m}$ ) with the horizontal radar. We used the flexible blip filtering controls in radR, where an $\mathrm{R}$ logical expression was used to further refine the blip filtering criteria (Taylor et al. 2010), to test radR's ability to filter out these false targets in the radar data. We applied an $\mathrm{R}$ expression to filter patches where the perimeter of the detected blip was disproportionately large compared to its area (Equation 1).

$$
\frac{\text { perim }^{2}}{\operatorname{area} *(4 * p i)}<5
$$

These characteristics were indicative of false targets, such as insects, but tend not to be associated with the desired true targets, such as birds and bats. Using this expression, a true target was assumed to be circular in shape and was measured as a scale invariant index by squaring its perimeter. True targets of similar shape will have a similar index regardless of their size. Targets that were at least five times as irregular as a circle were filtered out. We also tested the addition of an intensity filter (int $>0.3$ ) to the above area expression equation to eliminate targets with both diffuse area and low signal-return intensity (Equation 2).

$$
\frac{\text { perim }^{2}}{\operatorname{area} *(4 * \text { pi })}<5 \& \text { int }>0.3 \quad \text { [Eq. 2] }
$$

We assumed that aerial vertebrate targets were predominantly birds, and refer to them as such hereafter for simplicity. We ran a paired analysis from 12 nights where 15 min periods of radar data were gathered during three time periods within each night where visual and nightvision data confirmed: 1 ) insects were predominant (twilight period; $\mathrm{n}=12$ ); 2) both birds and insects were present (post-twilight to midnight; $\mathrm{n}=12$ ); and, 3) where birds were predominant (midnight to approximately $02: 00 ; \mathrm{n}=12$ ). For each grouping, we determined the total number of targets using: the full logical expression filter with the filter (Equation 2); the logical 
expression filter without the intensity expression (Equation 1); and, with no logical expression filter. We anticipated that the number of tracked targets should not only decrease when the filters were applied (as false targets were being eliminated), but that the magnitude of this target reduction should be greatest during periods of the nights where the number of known false targets was greatest (twilight period). Target reduction should be lowest during periods of the night where most of the targets were aerial vertebrates (midnight to 02:00). We calculated the proportion of targets removed by the Full (logical expression plus intensity (e.g. Eq 2) and Partial (logical expression only Eq 1) filters compared to the same trials non-filtered. We compared the proportion of targets filtered among the different categories using a Friedman ANOVA.

There was a significant difference in the number of targets filtered between the different biological target categories under Full filter (Friedman ANOVA: $\chi^{2}=15.0 ; P=0.001$ ). To determine where this difference lay, we conducted a multiple comparison following a Friedman test (Conover 1999) of the three treatment types (predominately birds, predominately insects or mixed insects/birds). The reduction in proportion of targets tracked was significantly greater in periods of the night where targets were predominantly insect-like returns, compared to periods that were predominantly avian targets $(P<0.05)$ or when both insects and birds were present $(P$ $<0.05)$. There were no differences in target reduction between periods of mixed insect/bird versus predominantly birds (Fig. S2). Use of the Partial filter yielded almost identical results 


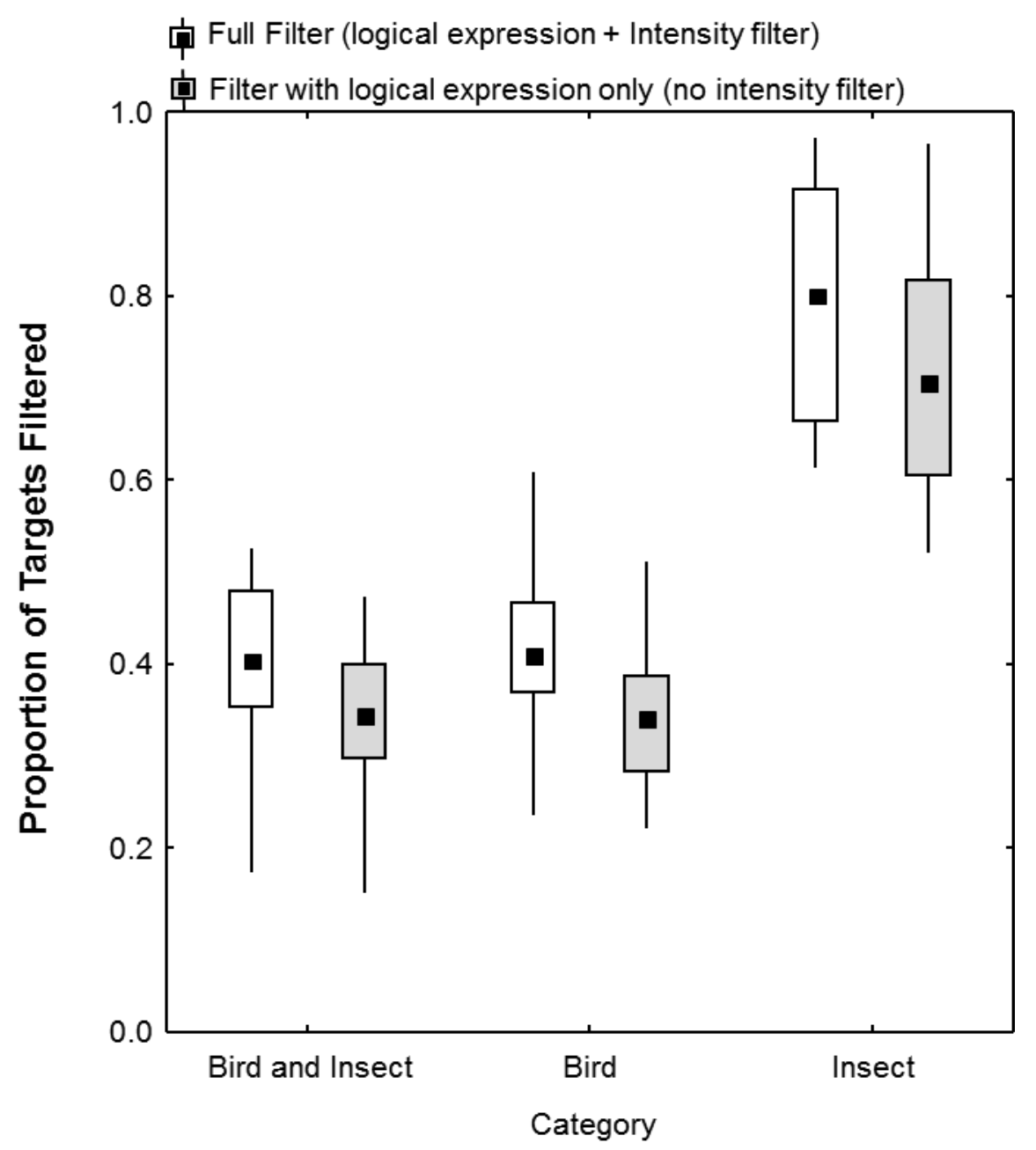

Fig. A1.2. The proportion of tracked targets removed by the use of Full and Partial filters compared to the same data without filters. Full Filter includes the logical expression and intensity filter - Eq 2 - and Partial Filter includes only the logical expression filter - Eq. 1. Data represents 12 nights of sampling where 15 min periods of the night when the targets were predominantly insect samples (dusk), predominantly bird samples (middle of night in cooler weather) and the bird and insect samples (period between dusk and midnight). Data was collected at the Dokie I Wind Energy Project from 2008 to 2012. Filtering removed a greater proportion of targets under periods of predominantly insect traffic, suggesting the Full Filter expression can reliably help reduce insect targets. 